\title{
ЭКОЛОГИЧЕСКАЯ ХАРАКТЕРИСТИКА КОНСТРУКЦИЙ ГАЗО-ПЫЛЕЗАЩИТНЫХ ЛЕСОПОЛОС АВТОМОБИЛЬНЫХ ДОРОГ
}

\author{
Ovcharuk Oleh \\ Sheludchenko Lesya \\ Hutsol Taras
}

State Agrarian and Engineering University in Podilia, Ukraine

DOI: https://doi.org/10.31435/rsglobal_ejits/30112018/6216

\section{ARTICLE INFO}

Received 16 July 2018

Accepted 14 November 2018

Published 30 November 2018

\section{KEYWORDS}

ecological safety,

motor road,

gas-dust protection forest belt,

fractal invariance.

\begin{abstract}
The ecological characteristic of gas-dust protection forest belts of motor roads is carried out in the article, depending on structural features. The parameters of wood-shrub gas-dust protective forest belts are proved by the methods of fractal-invariant modeling.
\end{abstract}

Citation: Ovcharuk Oleh, Sheludchenko Lesya, Hutsol Taras. (2018) Ekologicheskaya Harakteristika Konstrukcii Gazo_Pilezaschitnih Lesopolos Avtomobilnih Dorog. European Journal of Intelligent Transportation Systems. 1(1). doi: 10.31435/rsglobal_ejits/30112018/6216

Copyright: (C) 2018 Ovcharuk Oleh, Sheludchenko Lesya, Hutsol Taras. This is an open-access article distributed under the terms of the Creative Commons Attribution License (CC BY). The use, distribution or reproduction in other forums is permitted, provided the original author(s) or licensor are credited and that the original publication in this journal is cited, in accordance with accepted academic practice. No use, distribution or reproduction is permitted which does not comply with these terms.

Введение. Одним из наиболее эффективных видов экологической защиты придорожных ландшафтов является создание искусственных геохимических двусторонних защитных барьеров, которые отделяют проезжую часть автомобильной дороги от прилегающих территорий. В большинстве случаев такими барьерами являются газо-пылезащитные лесополосы древесно-кустарникового типа, которые выполняют противоэрозионные, снегозащитные, газо-пылезащитные, шумозащитные и декоративные функции. Вместе с тем, такое многофункциональное назначение древесно-кустарниковых защитных лесополос без учета ландшафтных особенностей конкретной природно-техногенной геоэкосистемы и таких характеристик автотранспортных потоков, как их интенсивность и плотность, не в состоянии в полной мере обеспечить экологически безопасные условия функционирования сети автомобильных дорог $[4,6]$.

Литературный обзор. Установлено, что любое антропогенное влияние на природно-территориальный комплекс связано с “конструированием” искусственных структур, для которых их фрактальная инвариантность не соответствует, как правило, фрактальным свойствам природных объектов и структур. Несоответствие фрактальных размерностей искусственно созданных (техногенных) и природных составляющих природно-техногенной геоэкосистемы приводит к образованию структур с композициями, которые сильно отличаются от композиции структуры исходного 
природно-территориального комплекса. Новая композиция структуры природнотехногенной геоэкосистемы и композиция структуры исходного природнотерриториального комплекса в этом случае являются антагонистичными друг другу, что и обуславливает определенный уровень экологической опасности антропогенной деятельности $[1,2,3]$.

Таким образом, одним из возможных путей предотвращения экологической опасности техногенной трансформации природно-территориальных комплексов является максимально возможное соответствие фрактальных размерностей искусственно создаваемых объектов природно-техногенных геоэкосистем фрактальным размерностям природно-территориальных комплексов [6]. Так, при проектировании автотранспортной сети региона должны быть обязательно установлены фрактальные размерности его природно-ландшафтных объектов, фрактальная структура составляющих экологически безопасной автотранспортной емкости территории, которые соответствуют репродуктивным возможностям природно-территориального комплекса и проектируемой структуре природно-техногенной геоэкосистемы. По результатам этих исследований должен быть разработан “опорный каркас" сети автомобильных дорог, как фрактальная модель природно-техногенной системы, генератор которой максимально возможно совпадает с генератором природно-ландшафтной структуры природно-территориального комплекса. После чего на основании фрактального анализа “опорного каркаса" сети автодорог с определяется топография полос отведения автомобильных дорог соответствующих категорий (с соответствующими плотностями и интенсивностями автотранспортных потоков), разрабатывается соответствующая автодорожная инфраструктура и проектируются отдельные объекты. При таком подходе к проектированию обеспечивается соблюдение фрактальной инвариантности структур искусственной техногенной инфраструктуры и природных структур природнотерриториального комплекса $[2,5,6]$.

Объект, цель и задач исследования. Объект исследования - процесс формирования газо-пылезащитной лесополосы древесно-кустарникового типа.

Целью работы является разработка обобщенной фрактально-инвариантной модели газо-пылезащитных лесополос автомобильных дорог различных категорий с разной плотностью и интенсивностью потоков автотранспортных средств.

Изложение основного материала. По результатам предыдущих исследований [7, 8] фрактально-инвариантных свойств сети автомобильных дорог и потоков автотранспортных средств были определены значения конструктивной ширины газопылезащитных лесополос автодорог в зависимости от категории автомобильной дороги и интенсивности движения автотранспортных средств.

Результаты этих исследований представлены в таблице 1.

Таблица 1. Результаты определения конструктивной ширины газопылезащитных лесополос автотранспортной сети в зависимости от категории автодороги и интенсивности движения автотранспортных средств

\begin{tabular}{ccccccc}
\hline Категория автодороги & $1-\mathrm{a}$ & $1-б$ & 2 & 3 & 4 & 5 \\
\hline $\begin{array}{c}\text { Расчетный коэффициент } \\
\text { интенсивности движения, } D_{m},[1 / \mathrm{M}]\end{array}$ & 500 & 350 & 250 & 133 & 71 & 44 \\
\hline $\begin{array}{c}\text { Фрактальная размерность, } \mu \\
\text { модельная ширина дорожной зоны, }\end{array}$ & 104 & 68 & 45 & 29 & 18 \\
\hline $\begin{array}{c}\text { м } \\
\text { Модельная ширина защитной } \\
\text { лесополосы, м }\end{array}$ & 32,25 & 23,25 & 15,75 & 8,0 & 3,75 \\
\hline $\begin{array}{c}\text { Конструктивная ширина защитной } \\
\text { лесополосы, м }\end{array}$ & 32 & 24 & 16 & 8 & 4 \\
\hline Конструктивная погрешность & 0,007 & 0,031 & 0,047 & 0,0 & 0,063 \\
\hline
\end{tabular}


Для построения контура и структуры поперечного сечения газо-пылезащитной лесополосы древесно-кустарникового типа, как исходного профиля, был использован идеализированный эвклидов треугольник [7], как обобщение рекурсии Коха с генерирующей размерностью в виде функции $G(D)$, которая совпадает с размерностью Хаусдорфа-Безиковича и в данном случае определяется как:

$$
\mu=G(D)=\Sigma r_{m}^{D}
$$

где $r_{m}^{D}$ - генератор фрактала Коха.

Размерность самоподобных фракталов Коха в данном случае варьирует от $\mu=$ $1,4490$ (рис. $1 a)$ до $\mu=1,8797$ (рис. 16 ).

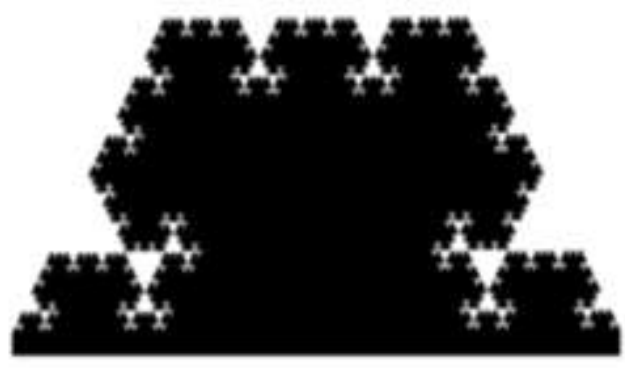

$a$

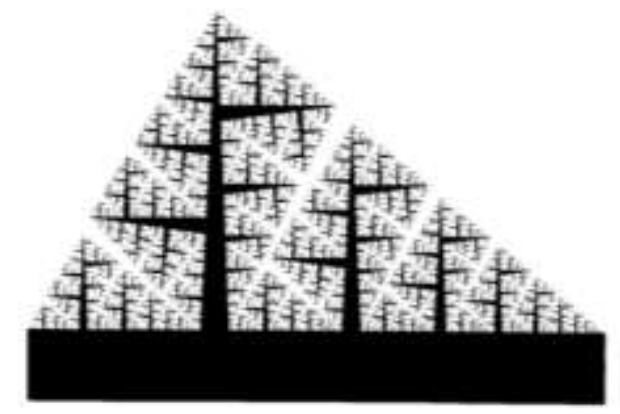

6

Pис. 1. Обобщенные самоподобные кривые Коха: $a-\mu=1,4490 ; \sigma-\mu=1,8797$ (фрактал Пеано-Пойа)

Газо-пылезащитная лесополоса изолирующего типа предусматривает трехъярусную структуру древесных и кустарниковых пород (рис. 2), которые в плане должны быть размещены в такой последовательности (рис. 3) [6]:

$$
Y \leftrightarrow \Gamma \leftrightarrow Y \leftrightarrow C \leftrightarrow Y \leftrightarrow \Gamma \leftrightarrow \ldots \leftrightarrow Y \leftrightarrow C \leftrightarrow Y
$$

где $\Gamma$ - основная древесная порода;

$C$ - сопутствующая древесная порода;

$Ч$ - кустарник.

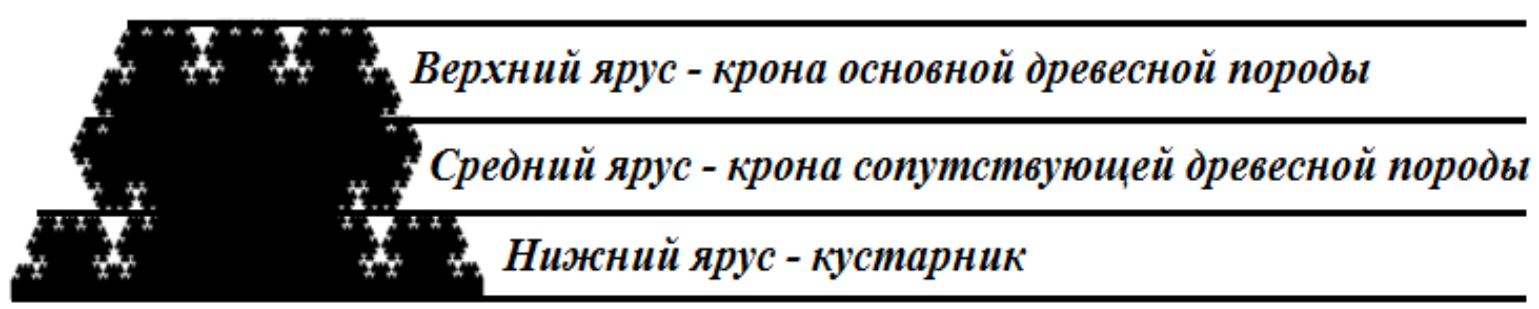

Рис. 2. Структура древесных и кустарниковых ярусов фрактальной модели газо-пьлезащитной лесополосы 


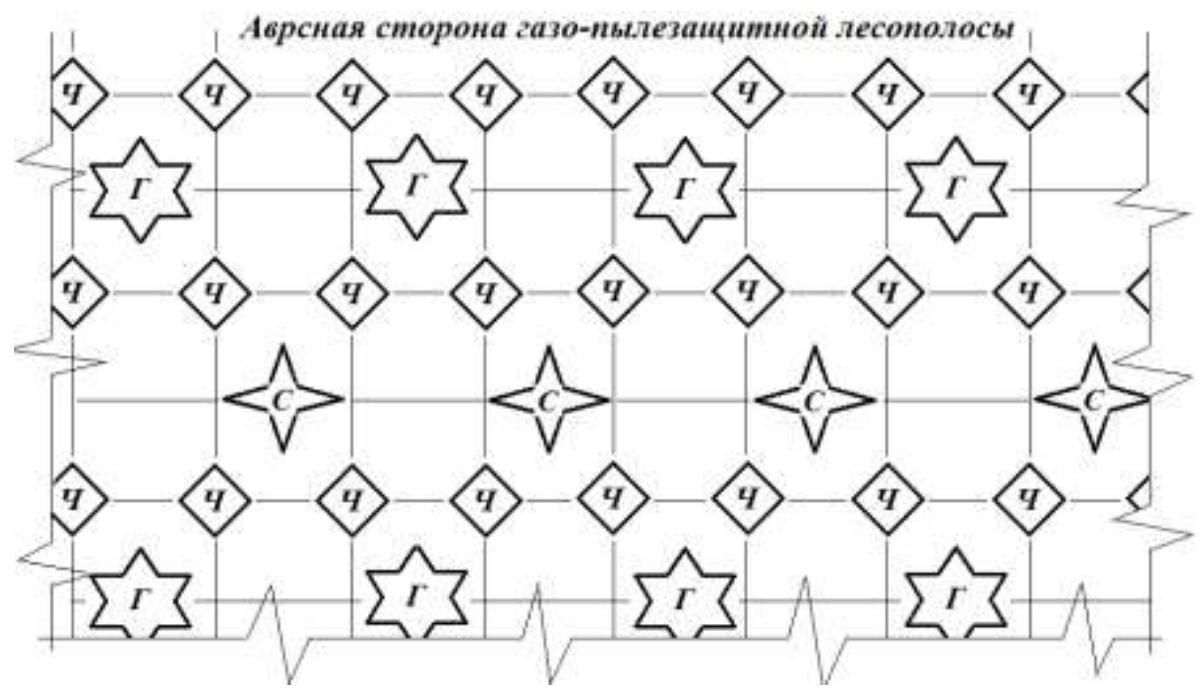

Рис. 3. Модель структуры посадки (в плане) древесных и кустарниковых пород газо-пылезащитных лесополос: Г-основная древесная порода;

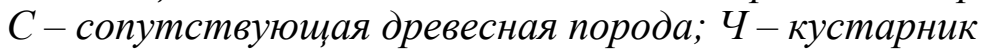

На основании основного определения фрактала “как части подобной целому”, для которого его фрактальная размерность (размерность Хаусдорфа-Безиковича) есть строго большей чем топологическая $\mu>\mu_{T}$, из фрактала Пеано-Пойя были выделены модельные составляющие основной древесной породы, сопутствующей древесной породы и кустарника. Процедура выделения приведенных составляющих представлена на рис.4.

Для определения угла наклона боковых (аверсной и реверсной) сторон профиля поперечного сечения газо-пылезащитной лесополосы (рис. 5) использована теория переноса и рассеивания примесей в приземном слое турбулентной атмосферы при наличии геохимических барьеров в природно-техногенной геоэкосистеме. В общем виде концентрация $q$ аэрозольной субстанции, которая находится элементарном объеме воздуха, который мигрирует с потоком воздуха атмосферы, является функцией пространственных координат и времени [6]:

$$
q=q(x, y, z, t) .
$$

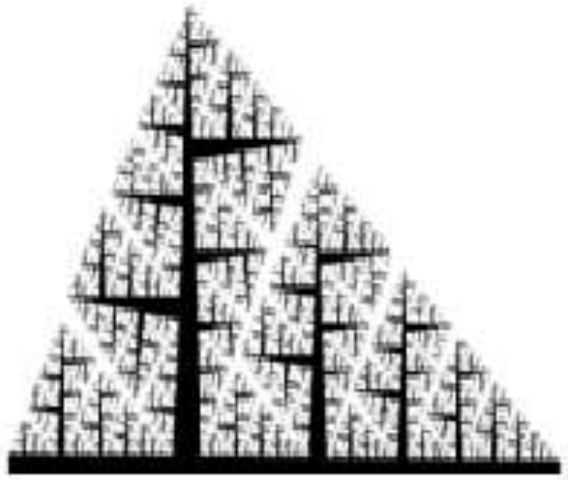

$a$

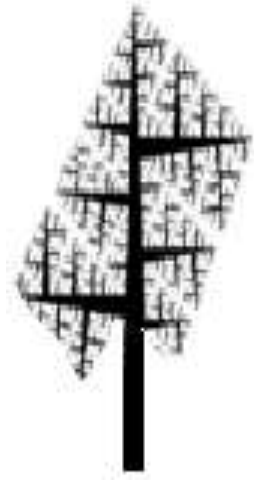

б

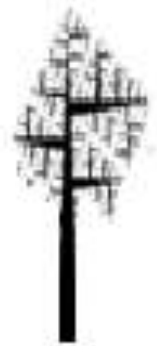

B

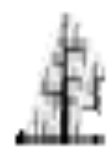

2

Рис.4. Прочедура выделения модельных составляющих газо-пылезащитной лесополосы древесно-кустарникового типа из фрактала Пеано-Пойя: а-исходный фрактал,

б - фрактальная модель главной древесной породы; в - фрактальная модель сопутствующей древесной породы, г - ррактальная модель кустарника 
Тогда, если $p\left(\vec{X}, t, \vec{X}^{\prime}, t_{0}\right)$ - вероятность перемещения элементарного объема воздуха, который содержит примесь с концентрацией $q\left(\vec{X}^{\prime}, t_{0}\right)$, из точки $\mathrm{c}$ пространственными координатами $\vec{X}^{\prime}$ в момент времени $t_{0}$ в точку с пространственными координатами $\vec{X}$ в момент времени $t$, то среднее значение концентрации примеси в точке пространства $\vec{X}$ в момент времени $t$, уменьшенное на некоторую величину действием геохимического барьера, составит:

$$
q(\vec{X}, t)<\int p\left(\vec{X}, t, \vec{X}^{\prime}, t_{0}\right) \cdot q\left(\vec{X}^{\prime}, t_{0}\right) \cdot d \vec{X}^{\prime} .
$$

Интегрирование правой части (4) выполненное во всех точках пространства приводит к распределению концентраций примесей (в вероятностном виде) по трехмерному пространству в момент времени $t$, если известно начальное распределение $q\left(\vec{X}^{\prime}, t_{0}\right)$ и вероятность всех перемещений элементарных объемов в этом пространстве - $p\left(\vec{X}, t, \vec{X}^{\prime}, t_{0}\right)$. При этом, $\int p\left(\vec{X}, t, \vec{X}^{\prime}, t_{0}\right) \cdot d \vec{X}^{\prime}=1$.

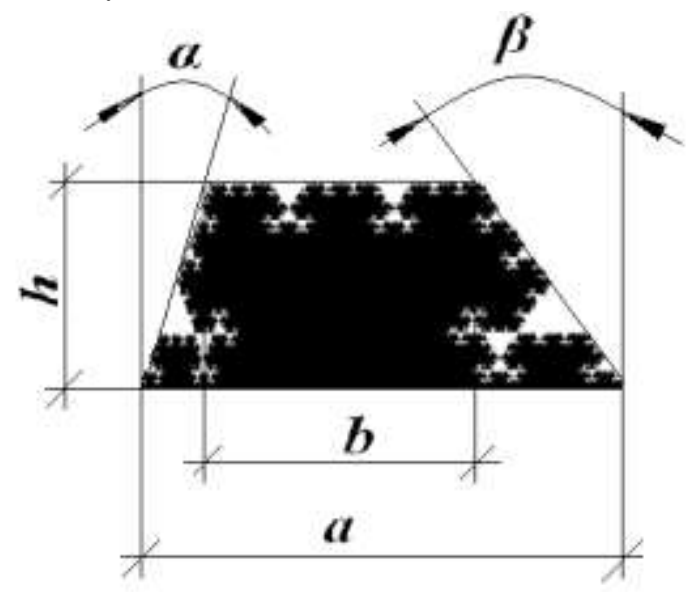

Рис. 5. Геометрические параметры профиля поперечного разреза газо-пылезащитной полосы древесно-кустарникового типа

Примесь, которая попадает в турбулентную среду, под действием пульсаций скорости потока, начинает распространяться в этой среде, образовывая при этом загрязненную область (таксонометрическую ячейку загрязнения). Выбор способа описания этого процесса зависит от способа поступления примеси в природнотехногенную геоэкосистему и от конечного требуемого результата [6]. Поэтому, для обеспечения максимально возможной эффективности действия проектируемой газопылезащитной полосы, необходимо обеспечить:

$$
q(\vec{X}, t)<<q\left(\vec{X}^{\prime}, t_{0}\right) .
$$

С учетом уравнения Бернулли:

$$
p+\frac{1}{2} \rho V^{2}=\text { const }
$$

где $p$ - давление атмосферного воздуха в воздушном потоке;

$\rho$ - плотность воздуха;

$V$ - скорость воздушного потока;

и в соответствии с обозначениями, которые приведены на рис.5 выражение (5) примет вид:

$$
\vec{X}-\vec{X}^{\prime}=\Delta q<h\left(\frac{1}{\cos \alpha}+\frac{1}{\cos \beta}\right)+a\left(1-\frac{1}{\sin \alpha}+\frac{1}{\sin \beta}\right)
$$

где $\alpha$ - угол наклона аверсной стороны профиля газо-пылезащитной лесополосы; $\beta$ - угол наклона реверсной стороны профиля газо-пылезащитной лесополосы. 
Учитывая, что значение высоты $h$ газо-пылезащитной лесополосы древеснокустарникового типа определяется биологическими свойствами основной древесной породы, а ее ширина $a$, определяется категорией автодороги, анализ соотношения углов наклона аверсной $(\alpha)$ и реверсной $(\beta)$ сторон профиля поперечного сечения лесополосы выполняем при помощи выражения:

$$
\Delta q_{\text {opt }}=\frac{\cos \beta+\cos \alpha}{\cos \alpha \cdot \cos \beta}+\left(1-\frac{\sin \beta+\sin \alpha}{\sin \alpha \cdot \sin \beta}\right) .
$$

Оптимизация значения угла $\beta$ наклона реверсной стороны газо-пылезащитной лесополосы выполнена симплекс-методом [?], при фиксированных значениях угла $\alpha$ наклона аверсной стороны лесополосы $\left(0^{\circ}<\alpha<20^{9}\right)$, которые обусловлены биологическими свойствами используемых древесных и кустарниковых пород. Результаты анализа (8) представлены на рис.6. Установлено $\beta_{o p t}=30^{\circ}-50^{\circ}$.

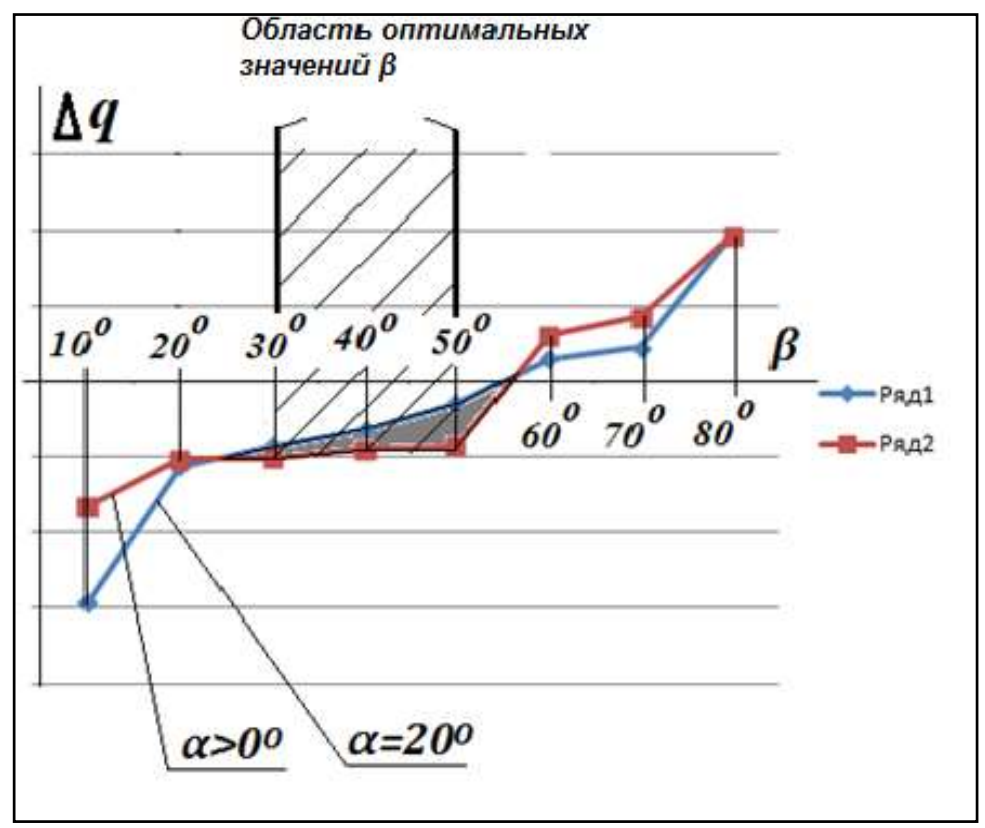

Рис. 6. Определение области оптимальных значений угла $\beta$ наклона реверсной стороны профиля газо-пылезащитнной лесополосы автодороги

По результатам аналитических исследований основных параметров структурной композиции и геометрических параметров профиля поперечного сечения газопылезащитных лесополос древесно-кустарникового типа сети автомобильных дорог предложены их фрактально-инвариантные модели для автодорог соответствующих категорий, которые представлены на рис. 7.

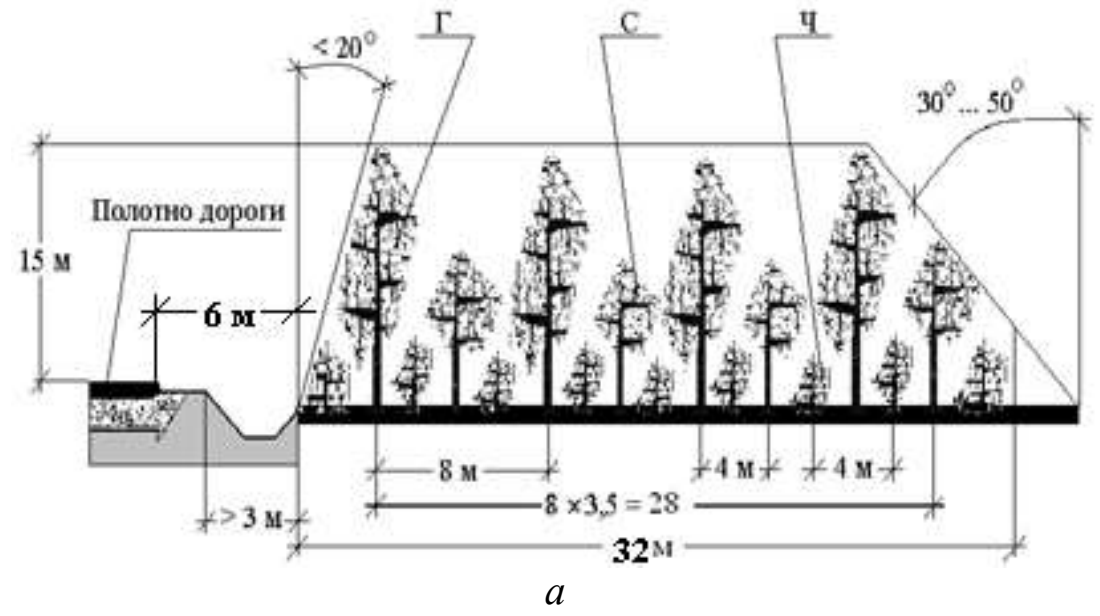




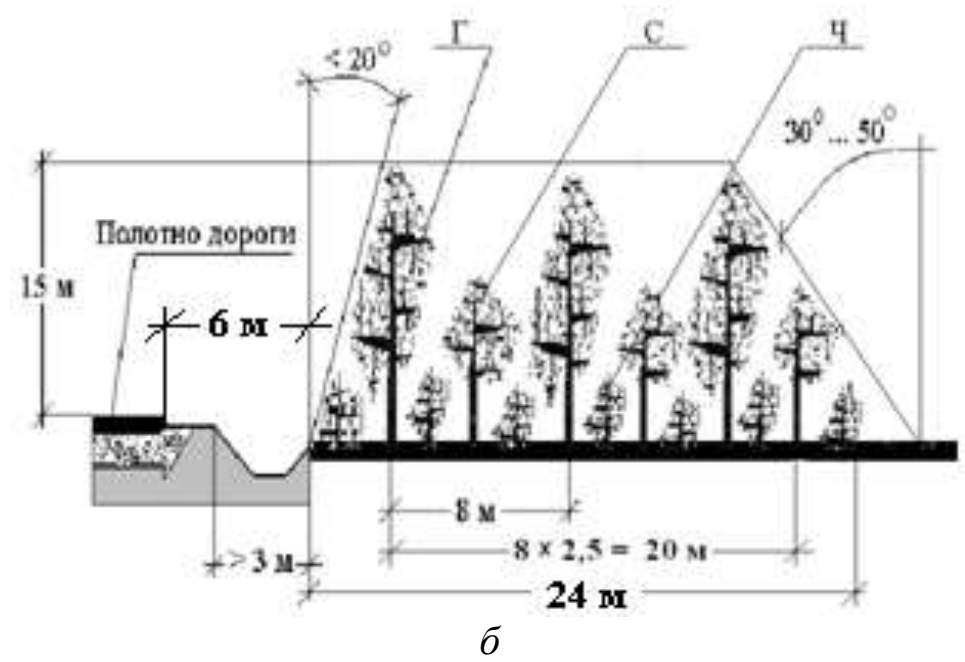

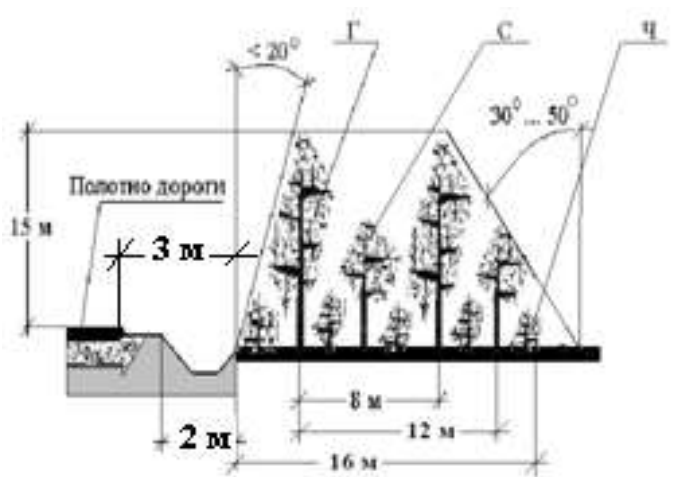

B

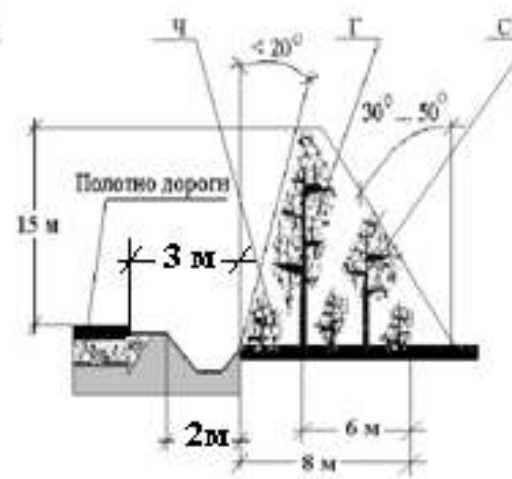

2

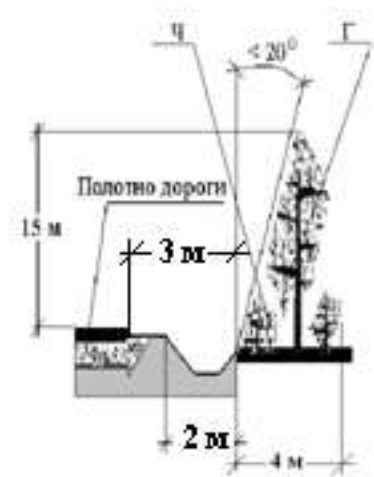

$\partial$

Рис. 7. Фрактально-инвариантные модели газо-пьлезащитных лесополос автомобильных дорог в зависимости от категории автодороги:

а-категории 1 - а, 1 - б; б-категория 2; в-категория 3; г-категория 4; $\partial-$ категория 5;

$\Gamma$ - основная древесная порода; $C$ - сопутствующая древесная порода; Ч - кустарник

Конструктивная привязка представленных моделей газо-пылезащитных полос к полотну проезжих частей автомобильных дорог выполнена в соответствии с нормативным документом ДБН В.2.3 - 4 - 2000 (Украина).

Выводы. По результатам аналитического обоснования конструкционных параметров древесно-кустарниковых газо-пылезащитных лесополос автомобильных дорог установлено:

1. Конструкционные параметры древесно-кустарниковой газо-пылезащитной лесополосы определяются в зависимости от категории автомобильной дороги, интенсивности автотранспортных потоков и с учетом транспортной емкости территории конкретной природно-техногенной геоэкосистемы.

2. Поперечным сечением профиля древесно-кустарниковой газо-пылезащитной лесополосы автодороги является трапеция с такими геометрическими параметрами:

- ширина лесополосы в зависимости от категории автодороги: 1а, 16 - 32 м; $3-16 \mathrm{~m} ; 4-8 \mathrm{~m} ; 5-4 \mathrm{~m}$;

- высота лесополосы (зависит от биологических особенностей деревьев и кустарников) для всех категорий автодорог -> 15 м;

- угол наклона боковых сторон лесополосы (от вертикальной плоскости) составляет: для аверсной стороны $-20^{\circ}$; для реверсной стороны $-30-50^{\circ}$. 


\section{REFERENCES}

1. Meteorologiya i klimatologiya / [pid red. S.M. Stepanenka]. - Odesa: Odes `ky`j derzhavny`j ekologichny`j universy`tet, 2008. - $534 \mathrm{~s}$.

2. Mandel'brot B. Fraktal'naya heometryya pryrody / B. Mandel'brot. - M.: Yn-t komp'yuternykh yssledovanyy, 2002. - $656 \mathrm{~s}$.

3. Kozina, T., Ovcharuk, O., Trach, I., Levytska, V., Ovcharuk, O., Hutsol, T., Mudryk, K., Jewiarz, M., Wróbel, M., Dziedzic, K. Spread Mustard and Prospects for Biofuels. Renewable Energy Sources. Engineering, Technology, Innovation: ICORES 2017, 2018. 791-799. DOI 10.1007/978-3-319-72371-6_77.

4. Ovcharuk O. Ekologo-texnologichna opty mizaciya opornogo karkasu avtodorozhnoyi merezhi /L.S. Sheludchenko, O.V. Ovcharuk, O.S. Chynchyk, V.L. Nosko /Racional’ne vy`kory`stannya resursiv v umovax ekologichno stabil`ny`x tery`torij: kolekty`vna monografiya / za red. P.V. Py`sarenka, T.O. Chajky`, I.O. Yasnolob. - Poltava. TOV NVP «Ukrpromtorgservis», 2018. - s. 300-310. ISBN 978-6177464-15-9.

5. Rud'ko G.I., Adamenko O.M. The Structural geoecology. Kyiv.: LTD. "Maklaut", 2008. - 320 p.

6. Sheludchenko L.S., Ovcharuk O.V. Model-simulator of windbreak// Ekolohichna bezpeka 2/2011 (12). Kremenchuk. - 2011. - S. 76-79.

7. Sheludchenko B.A. Vstup do konstruyuvannya pryrodno-tekhnohennykh heoekosystem (landshaftnoterytorial'nyy aspekt) / B.A. Sheludchenko. - Kamyanets'-Podil's'kyy: Vyd-vo PDATU, 2014. - $170 \mathrm{~s}$.

8. Sheludchenko L.S. Obgruntuvannya ekoloho-landshaftnykh parametriv ta rozroblennya konstruktsiy hazopylozakhysnykh smuh avtodorozhn'oyi merezhi: dys. ... kand. tekhn. nauk: 21.06.01. / L.S. Sheludchenko. - Kam"yanets'-Podil's'kyy, 2013. - 181 s. 